Subscriber access provided by BNL Research Library

Communication

\title{
Sodiation Kinetics of Metal Oxide Conversion Electrodes: a Comparative Study with Lithiation
}

Kai He, Feng Lin, Yizhou Zhu, Xiqian Yu, Jing Li, Ruoqian Lin, Dennis Nordlund, Tsu-Chien Weng, Ryan M. Richards, Xiao-Qing Yang, Marca Doeff, Eric A. Stach, Yifei Mo, Huolin L. Xin, and Dong Su

Nano Lett., Just Accepted Manuscript • Publication Date (Web): 19 Aug 2015

Downloaded from http://pubs.acs.org on August 19, 2015

\section{Just Accepted}

"Just Accepted" manuscripts have been peer-reviewed and accepted for publication. They are posted online prior to technical editing, formatting for publication and author proofing. The American Chemical Society provides "Just Accepted" as a free service to the research community to expedite the dissemination of scientific material as soon as possible after acceptance. "Just Accepted" manuscripts appear in full in PDF format accompanied by an HTML abstract. "Just Accepted" manuscripts have been fully peer reviewed, but should not be considered the official version of record. They are accessible to all readers and citable by the Digital Object Identifier (DOI®). "Just Accepted" is an optional service offered to authors. Therefore, the "Just Accepted" Web site may not include all articles that will be published in the journal. After a manuscript is technically edited and formatted, it will be removed from the "Just Accepted" Web site and published as an ASAP article. Note that technical editing may introduce minor changes to the manuscript text and/or graphics which could affect content, and all legal disclaimers and ethical guidelines that apply to the journal pertain. ACS cannot be held responsible for errors or consequences arising from the use of information contained in these "Just Accepted" manuscripts. 


\title{
Sodiation Kinetics of Metal Oxide Conversion Electrodes: a Comparative Study with Lithiation
}

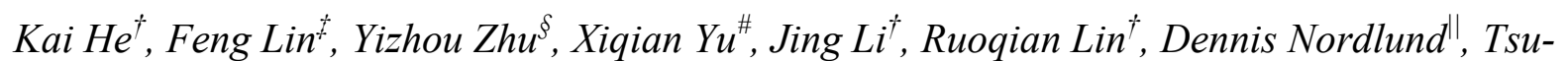
Chien Weng ${ }^{\|}$, Ryan M. Richards ${ }^{\perp}$, Xiao-Qing Yang ${ }^{\#}$, Marca M. Doeff ${ }^{\star}$,Eric A. Stach ${ }^{\dagger}$, Yifei $\mathrm{Mo}^{\S,}$, Huolin L. Xin ${ }^{\dagger, *}$, and Dong Su ${ }^{\dagger, *}$

${ }^{\dagger}$ Center for Functional Nanomaterials, Brookhaven National Laboratory, Upton, New York 11973, USA.

†Energy Storage and Distributed Resources Division, Lawrence Berkeley National Laboratory, Berkeley, CA 94720, USA.

${ }^{\S}$ Department of Materials Science and Engineering, University of Maryland, College Park, MD 20742, USA.

${ }^{\text {\#} C h e m i s t r y ~ D e p a r t m e n t, ~ B r o o k h a v e n ~ N a t i o n a l ~ L a b o r a t o r y, ~ U p t o n, ~ N e w ~ Y o r k ~ 11973, ~ U S A . ~}$

"Stanford Synchrotron Radiation Lightsource, SLAC National Accelerator Laboratory, Menlo Park, California 94025, USA.

${ }^{\perp}$ Department of Chemistry and Geochemistry, Materials Science Program, Colorado School of Mines, Golden, Colorado 80401, USA.

*E-mails: yfmo@umd.edu; hxin@bnl.gov; dsu@bnl.gov

\begin{abstract}
:
The development of sodium ion batteries (NIBs) can provide an alternative to lithium ion batteries (LIBs) for sustainable, low-cost energy storage. However, due to the larger size and higher $\mathrm{m} / \mathrm{e}$ ratio of the sodium ion compared to lithium, sodiation reactions of candidate electrodes are expected to differ in significant ways from the corresponding lithium ones. In this work, we investigated the sodiation mechanism of a typical transition metal-oxide, $\mathrm{NiO}$, through a set of correlated techniques, including electrochemical and synchrotron studies, real-time electron microscopy observation, and ab initio molecular dynamics (MD) simulations. We found that a crystalline $\mathrm{Na}_{2} \mathrm{O}$ reaction layer that was formed at the beginning of sodiation plays an
\end{abstract}


important role in blocking the further transport of sodium ions. In addition, sodiation in $\mathrm{NiO}$ exhibits a "shrinking-core" mode that results from a layer-by-layer reaction, as identified by $a b$ initio MD simulations. For lithiation, however, the formation of Li anti-site defects significantly distorts the local $\mathrm{NiO}$ lattice that facilitates $\mathrm{Li}$ insertion, thus enhancing the overall reaction rate. These observations delineate the mechanistic difference between sodiation and lithiation in metal-oxide conversion materials. More importantly, our findings identify the importance of understanding the role of reaction layers on the functioning of electrodes, and thus provide critical insights into further optimizing NIB materials through surface engineering.

KEYWORDS: Sodiation, kinetics, nickel oxides, reaction pathways, conversion electrodes.

TOC:

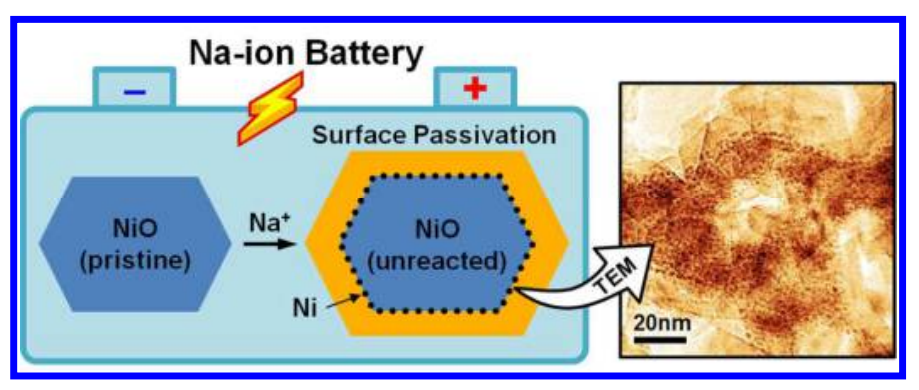

Lithium ion batteries (LIBs) have enjoyed great success as power sources for portable electronics and are emerging as energy storage systems of choice for electric vehicles. ${ }^{1}$ There have been also increasing interests in developing LIBs for grid storage applications. However, because of the high cost of the electrode materials and limited Li supplies, it is important to explore alternatives, such as a sodium-based battery, which can potentially offer a sustainable, low-cost solution for energy storage. ${ }^{2-9}$ Due to the many similarities between sodium and lithium 
chemistries, the development of sodium-ion batteries (NIBs), can benefit greatly from the knowledge developed over the past 25 years on LIBs, ${ }^{6-9}$ but differences in the lithiation and sodiation behaviors of electrode materials are evident. In the case of conversion anode materials for NIBs, only a few compounds have been found to be promising for sodiation reactions, such as the spinel $\mathrm{NiCo}_{2} \mathrm{O}_{4}{ }^{10}$ In transition metal oxides $\mathrm{MO}_{\mathrm{x}}(\mathrm{M}=\mathrm{Fe}$, Co and $\mathrm{Ni})$, the sodiation reactions have much lower capacities and slower kinetics than those commonly observed in lithiation reactions. ${ }^{11,12}$ The incorporation of cations in conversion electrode materials involves multiple processes, i.e., $\mathrm{Li}^{+} / \mathrm{Na}^{+}$diffusion into the electrode material, an electrochemical reaction between redox couples, and interfacial reactions between the electrode and electrolyte. Thus many parameters, such as electronic and ionic transport, the passivation layer formed at the electrode/electrolyte interface and the intrinsic reaction kinetics can affect the rate of the entire conversion reaction. To date, the specific rate-limiting steps for Na-ion batteries are not fully understood, even though the identification of these rate-limiting steps through direct characterization is critical for developing rechargeable NIBs. To address this question, we herein utilize multiple characterization techniques to present a comprehensive, correlated study of the sodiation and lithiation of a model $\mathrm{MO}_{\mathrm{x}}$ conversion compound, viz., simple rocksalt structured $\mathrm{NiO}$ that does not involve lithium intercalation or alloying.

It generally is believed that the differences in the ionic size of $\mathrm{Na}^{+}$and $\mathrm{Li}^{+}$are correlated with the differences observed in their transport kinetics, which, in turn, leads to their distinctive electrochemical behaviors. ${ }^{6-9}$ However, the influence of increasing ionic size is not always intuitive. ${ }^{13-15}$ It has been reported that layered $\mathrm{NaMO}_{2}$ compounds $(\mathrm{M}=\mathrm{V}, \mathrm{Cr}, \mathrm{Mn}$, and $\mathrm{Fe})$ exhibit better intercalation kinetics and greater capacity than does $\mathrm{LiMO}_{2}$, due to differences in the stacking of transition-metal oxide layers, and the resulting preferred $\mathrm{Li} / \mathrm{Na}$ sites and 
occupancy. ${ }^{7,8}$ On the other hand, in materials undergoing conversion reactions, there are not necessarily ionic diffusion channels in the structures and the predominant reaction mechanisms are not based on intercalation. Rather, displacement reactions occur as shown in Eq (1):

$$
\mathrm{M}_{a} \mathrm{X}_{b}+b \cdot n(\mathrm{Li} / \mathrm{Na})^{+}+b \cdot n \mathrm{e}^{-} \rightarrow b(\mathrm{Li} / \mathrm{Na})_{n} \mathrm{X}+a \mathrm{M}
$$

where $\mathrm{M}$ is a transition metal, and $\mathrm{X}=\mathrm{O}, \mathrm{F}, \mathrm{N}$, or $\mathrm{S}$. The difference in the ionic sizes of $\mathrm{Na}^{+}$and $\mathrm{Li}^{+}$would not be expected to affect the reaction dynamics. ${ }^{12,16}$ Given these observations, we considered it valuable to investigate and compare sodiation and lithiation reactions of a conversion electrode with correlated approaches. In this study, we integrated the insights from a combination of multiple temporally and spatially-scaled characterization techniques, including electrochemical measurements, in situ transmission electron microscopy (TEM), ${ }^{17-27}$ and $a b$ initio molecular dynamics (MD) simulations to provide a comprehensive understanding of what governs the rate of sodiation of $\mathrm{NiO}$ nanosheets and compared it to the lithiation behavior.

$\mathrm{NiO}$ has been investigated as a conversion anode material for LIBs, ${ }^{11}$ and it is very stable under electron irradiation and suitable for TEM observation. ${ }^{27}$ The as-prepared NiO nanosheets in this study exhibit a 2D nature with nanoscale perforated holes on the (111) basal planes that may help to improve the reaction kinetics compared to that of micron-sized materials. ${ }^{27,28}$ The electrochemical measurements were performed in half-cells; i.e., sodium or lithium metal was used as negative electrodes, and nickel oxide as the positive one. The charge-discharge profiles show that the sodiation reaction delivers a significantly lower capacity than does the lithiation reaction (Figure 1a and S1) under identical cycling conditions. The first sodiation discharge and charge capacities, respectively, are only $480 \mathrm{mAh} \mathrm{g}^{-1}$ and $93 \mathrm{mAh} \mathrm{g}^{-1}$, which is both much lower than those typically reported in the case of lithiation and far from the theoretical sodiation 
capacity $\left(718 \mathrm{mAh} \mathrm{g}^{-1}\right)$. Figure $1 \mathrm{~b}$ presents the capacity retention and Coulombic efficiency for the sodium half-cell. Overall, the discharge/charge capacities gradually decreased starting from the second cycle (260 $\mathrm{mAh} \mathrm{g}^{-1}$ and $\left.96 \mathrm{mAh} \mathrm{g}^{-1}\right)$ and then stabilized after 40 cycles at $\sim 110 \mathrm{mAh}$ $\mathrm{g}^{-1}$ and $\sim 60 \mathrm{mAh} \mathrm{g}^{-1}$ respectively. In addition, the Coulombic efficiency as a function of cycle number never exceeded 40-55\%; much lower than that found in lithium half-cells. ${ }^{28}$ This difference likely is due to the irreversible side-reactions associated with the discharge (i.e., sodiation) process. To investigate the sodiation reaction further, we used the surface-sensitive probing capability of synchrotron soft X-ray absorption spectroscopy (XAS) in the total electron yield (TEY) mode to analyze the structural changes of electrodes as a function of their state-ofcharge (SOC), as shown in Figure 1c. In the first discharge, we observed that the characteristic O K-edge peak associated with the $\mathrm{Ni}_{3 d^{-}} \mathrm{O}_{2 p}$ hybridization state in the pristine $\mathrm{NiO}$ gradually decayed, while the $\pi^{*}(\mathrm{C}=\mathrm{O})$ peak attributed to carbonate groups formed as the sodiation reaction proceeded. The carbonates may be resulted from the electrolyte decomposition during sodiation at the surface of $\mathrm{NiO} .{ }^{28-31}$ The absolute intensity of Ni L-edge in the TEY mode decreased as the thickness of carbonate groups built up (Figure 1c, right panel). After a complete cycle the carbonate-enriched layer did not decompose completely: this is similar to the behavior observed in lithium half-cells. ${ }^{28}$ The probing depth of XAS in the fluorescence yield (FY) mode reaches $50-100 \mathrm{~nm}$, which is far beyond the thickness of the NiO nanosheets studied here, thus XAS/FY is bulk sensitive for $\mathrm{NiO}$ nanosheets. The normalized XAS fluorescence yield from the nickel Ledge (Figure $\mathrm{S} 2$ ) exhibits similar $\mathrm{L}_{3} / \mathrm{L}_{2}$ ratios and similar near-edge features (i.e., no significant change in oxidation state) throughout the entire sodiation process, indicating that the majority of $\mathrm{NiO}$ remains unreacted. This is likely due to the fact that the sodiation reaction primarily occurred only at the surface of $\mathrm{NiO}$ nanosheets. To justify this hypothesis, representative images 
of the morphology of the electrode material after a full discharge are shown in the ex situ TEM image (Figure 1d), where only the surface of the $\mathrm{NiO}$ was sodiated to a shallow depth. This resulted in the formation of Ni nanoparticles, an observation that is in a good agreement with the Ni L-edge XAS/FY results and the low cycling capacity of sodiation. In contrast, we observed that nickel oxide is fully reduced to metallic nickel when the voltage reached the lower limit of the cycling voltage window in lithium half-cells. ${ }^{27,28}$

From these observations, we may attribute the inferior sodiation capacity to either the passivation effect of the surface reaction layers and/or the intrinsically slow reaction between $\mathrm{Na}^{+} / \mathrm{e}^{-}$and $\mathrm{NiO}$. Previous studies have shown that the surface $\mathrm{Li}_{2} \mathrm{O}$ may partially react with the organic electrolyte to form a lithium carbonate-containing passivation layer. ${ }^{28,29}$ Based on the similarity between these two systems, we assume that a surface reaction layer (likely sodium carbonates) would be formed from a similar reaction with $\mathrm{Na}_{2} \mathrm{O}$ in a sodium cell containing organic carbonate electrolytic solutions, as suggested by the XAS data (formation of $\pi^{*}(\mathrm{C}=\mathrm{O})$, Figure 1c). However, the entire interfacial layer may be very complicated in the real battery systems, which may comprise a $\mathrm{Na}_{2} \mathrm{O}$ layer (as a reaction product), an inorganic surface carbonate-enriched layer, and an organic carbonate layer from the decomposition of electrolyte. ${ }^{31}$ The latter two layers should have similar properties to the interfacial layers in other lithium-ion electrode systems, which should be ionically conducting. ${ }^{31}$ In our case, because of the possibility of extensive damage during exposure to electron beam and air moisture, the organic surface layer cannot be studied directly using TEM. To eliminate the influence of the organic electrolytic solution, we studied sodiation primarily using an in situ TEM approach, wherein inorganic $\mathrm{Na}_{2} \mathrm{O}$ or $\mathrm{Li}_{2} \mathrm{O}$ is used as the solid electrolyte. ${ }^{27}$ 
We carried out in situ TEM experiments using a dry-cell setup for both sodiation and lithiation, using only a $\mathrm{Na}_{2} \mathrm{O}$ or a $\mathrm{Li}_{2} \mathrm{O}$ solid electrolyte (Figure $2 \mathrm{a}$ ), in which $\mathrm{Na}^{+} / \mathrm{Li}^{+}$ions are transported under a positive bias with respect to the $\mathrm{NiO}$ electrode. Figure $2 \mathrm{~b}$ - $\mathrm{d}$ shows the selected area electron diffraction (SAED) patterns for pristine, sodiated, and lithiated samples, respectively, showing the existence of $\mathrm{Ni}$ and $\mathrm{Na}_{2} \mathrm{O} / \mathrm{Li}_{2} \mathrm{O}$ as reaction products, in consistent with what was found from the coin batteries. In addition, radial-intensity profiles as a function of sodiation/lithiation time were derived from the in situ SAED videos (Supporting Information Movie 3, and Movie 4 in ref. 27), as shown in Figure 2e,f. Diffraction peaks from pristine NiO and reaction products including $\mathrm{Ni}, \mathrm{Na}_{2} \mathrm{O}$, and $\mathrm{Li}_{2} \mathrm{O}$ were identified (Figure 2e,f and Figure $\mathrm{S} 3$ ). It is obvious that $\mathrm{NiO}$ is gradually converted into $\mathrm{Ni}$ and $\mathrm{Na}_{2} \mathrm{O}$ or $\mathrm{Li}_{2} \mathrm{O}$ as it reacts, respectively, with $\mathrm{Na}$ or Li. However, the lithiation process occurs at a much higher rate than the sodiation process (Figure 2g,h), in agreement with our electrochemical measurements. We also note that the Bragg peaks of $\mathrm{Na}_{2} \mathrm{O}$ phase have a much smaller full-width-at-half maximum (FWHM) compared to those of the $\mathrm{Li}_{2} \mathrm{O}$ and $\mathrm{Ni}$ phases (Figure 2i), suggesting that the crystal domain size of $\mathrm{Na}_{2} \mathrm{O}$ produced in sodiation is larger than the $\mathrm{Li}_{2} \mathrm{O}$ produced in lithiation (Figure $2 \mathrm{j}$ ). ${ }^{32}$

Figure 3a presents still images from a representative sodiation process captured by realtime TEM (Supporting Information Movie 1). These images were taken in a low-dose imaging mode so as to minimize electron beam induced damage and/or the growth of sodium/lithium compounds. At the initial stages of the observation (before recording the movie), a thin surface layer was observed almost immediately upon the delivery of $\mathrm{Na}^{+}$to the electrode via fast surface diffusion. This layer was confirmed to be $\mathrm{Na}_{2} \mathrm{O}$ from the diffraction pattern. After a short time (240 s), a large number of reduced Ni nanoparticles of ultrafine size $(\sim 1 \mathrm{~nm})$ started to become visible on the $\mathrm{NiO}$ surfaces, while the $\mathrm{Na}_{2} \mathrm{O}$ crystal continued to grow and plate out. Even after 
960s, only portions of the $\mathrm{NiO}$ nanosheets had reacted and the Ni nanoparticles gradually coarsened and became embedded in the $\mathrm{Na}_{2} \mathrm{O}$ layers. The Ni nanoparticles reached an ultimate average size of $\sim 3 \mathrm{~nm}$, and the $\mathrm{Na}_{2} \mathrm{O}$ layer thickened to greater than $10 \mathrm{~nm}$. The changes in phase and morphology observed here are consistent with the ex situ TEM observation in the coin cell with the organic electrolytic solution (Figure 1d). In contrast, the lithiation reaction went through a different, heterogeneous pathway, as shown in Figure 3b and Movie 2 (Supporting Information): $\mathrm{Li}^{+}$ions first diffused quickly over the surface of the $\mathrm{NiO}$ nanosheet, followed by a near-surface to interior transition via both "shrinking-core" and "finger" modes, consistent with our prior observations. ${ }^{27}$ The reaction fingers can expedite the conversion process and lead to a faster reaction in the bulk of the particle than occurs in the shrinking-core mode. ${ }^{27}$ In contrast, the characteristics of the finger reaction mode are not observed during the sodiation process in the in situ experiments, and the shrinking-core mode is also much slower during sodiation than during lithiation: these two observations can explain the low utilization observed in the Na coincells, shown in Figure 1.

We then characterized the reduced $\mathrm{NiO}$ sheets using aberration-corrected analytical STEM approaches, including annular dark-field scanning transmission electron microscopy (ADF-STEM), and electron energy-loss spectroscopy (EELS). We note that any surface layer (in both in situ and ex situ TEM specimens) can be damaged by exposure to the strong electron beam. $^{28}$ STEM-EELS mapping (Ni L-edges, Figure S4d) reveals a direct correlation between nickel reduction and the formation of Ni nanoparticles. Figure 4a presents a cross-sectional, high-resolution STEM image of a NiO slab along the [110] direction. It shows a nearly coherent atomic lattice between the $\mathrm{Ni}$ nanoparticles and the $\mathrm{NiO}$ nanosheet, as indicated by the fast Fourier transform (FFT). By filtering the FFT, we reconstructed the atomic arrangements of Ni 
atom columns for both the $\mathrm{NiO}$ and $\mathrm{Ni}$ phases (Figure $4 \mathrm{~b}$ ). Given that $\mathrm{NiO}$ has a broadly similar crystal structure to $\mathrm{Ni}$ (containing additional $\mathrm{O}$ atoms at the octahedral sites, as shown in Figure 4c), the phase transformation from $\mathrm{NiO}$ to $\mathrm{Ni}$ can be thought of as being equivalent to removing all of the $O$ (111) planes, with a consequent lattice shrinkage of $\sim 18.3 \%$ : this is in a good agreement with the measured (111) spacing difference of $\sim 14.8 \%$ (Figure $4 \mathrm{~b}$, inset).

A panoramic three-dimensional (3D) visualization of the sodiation structure was achieved using STEM tomography on a specimen that had been sodiated in situ, as shown in Figure 4d and Movie 4 (Supporting Information). The reconstructed 3D tomograms indeed reveal that the reduced metallic Ni nanoparticles (in orange) are only attached on the surface of the incompletely reacted $\mathrm{NiO}$ slab (in purple). This finding is in contrast to our prior observations of lithiation, wherein the metallic Ni nanoparticles are embedded in the $\mathrm{Li}_{2} \mathrm{O}$ to form a composite. $^{27,28}$ The data shown in Figure 4 and Figure S4 confirm that the reaction proceeds by the shrinking-core mode.

We demonstrated that the thicker $\mathrm{Na}_{2} \mathrm{O}$ layer formed during sodiation compared to lithiation will result in slower overall transport of $\mathrm{Na}^{+}$, as first-principles calculations predict similar formation energy and migration energy barriers of $\mathrm{Li}^{+}$in $\mathrm{Li}_{2} \mathrm{O}$ and $\mathrm{Na}^{+}$in $\mathrm{Na}_{2} \mathrm{O}$, respectively (Figure S6, Supporting Information). The fact that $\mathrm{Na}_{2} \mathrm{O}$ forms a thicker reaction layer than $\mathrm{Li}_{2} \mathrm{O}$ is partially the result of the large difference in the molar volume of $\mathrm{Na}_{2} \mathrm{O}$ compared to that of $\mathrm{Li}_{2} \mathrm{O}$ (factor of 2) and in addition to that in lithiation, part of $\mathrm{Li}_{2} \mathrm{O}$ is embedded into the composited structure of $\mathrm{Li}_{2} \mathrm{O} / \mathrm{Ni}$ which left less $\mathrm{Li}_{2} \mathrm{O}$ on the surface. Moreover, it is obvious from the diffraction study (Figure $2 \mathrm{j}$ ) that the $\mathrm{Na}_{2} \mathrm{O}$ reaction layer is crystalline with $\sim 4 \mathrm{~nm}$ crystal domain size. This is in strong contrast to $\mathrm{Li}_{2} \mathrm{O}$, where the grain 
size of $\mathrm{Li}_{2} \mathrm{O}$ is approximately $1 \mathrm{~nm}$. Thus, the $\mathrm{Na}_{2} \mathrm{O}$ passivation layer has far fewer grain boundaries per unit volume, which can further impede the diffusion of $\mathrm{Na}^{+}$.

We undertook ab initio MD simulations to clarify the atomistic processes of these reactions. Figure 5a illustrates the decrease in the total number of $\mathrm{Ni}-\mathrm{O}$ bonds in the MD simulation as a function of time, which is computational proxy for the rate of lithiation and sodiation. The MD simulations indicate that in the initial stage both the lithiation and the sodiation of the $\mathrm{NiO}$ proceed in a layer-by-layer fashion, wherein one atomic layer of $\mathrm{NiO}$ is reacted at a time. This reaction is initiated by the formation of $\mathrm{Li} / \mathrm{Na}$ anti-site defects at the $\mathrm{Ni}$ site. Simulations show that their formation significantly distorts the local NiO lattice (Figure 5c). This distortion facilitates further insertion of $\mathrm{Li}$, and thus enhances the overall rate of lithiation. In contrast, the formation of $\mathrm{Na}$ anti-site defects does not significantly distort the $\mathrm{NiO}$ lattice (Figure 5b), slowing down further sodiation reactions.

By combining the findings from MD simulations and TEM experiments, it is possible to describe the complete reaction mechanisms: the MD simulations provide insights into the atomistic scale mechanisms of the conversion reaction during lithiation and sodiation. Additional physical processes, such as the growth of the reaction products $\mathrm{Ni}$ and $\mathrm{Li}_{2} \mathrm{O} / \mathrm{Na}_{2} \mathrm{O}$, the local phase separation, and the strain balance resulting from the volume expansion are all captured in the TEM experiments at a longer timescale. In the incubation stage of the reactions, the kinetics of the conversion reaction are determined by the physical nature of $\mathrm{Na}^{+}$and $\mathrm{Li}^{+}$(their ionic radii and electronegativities): the reactions with $\mathrm{Na}$ ions occurs in a layer-by-layer fashion impeding further $\mathrm{Na}^{+}$insertion and enhancing the thickening of the $\mathrm{Na}_{2} \mathrm{O}$ surface layer. In contrast, heterogeneous reaction fronts, such as the finger-like features shown Figure 5d, are formed during lithiation, and are a result of a larger lattice distortion, as observed in the MD simulations. 
These finger-like reaction fronts enlarge into reaction fingers that greatly increase the overall rate performance of the conversion reaction (Figure 5d).

As a result of the intrinsically different reaction mechanisms of sodiation and lithiation, the formation of the surface layers are different in each case, as are the associated ionic transport properties. These passivation layers, in turn, play a critical role in determining the overall reaction rate. In particular, a $\mathrm{Na}_{2} \mathrm{O}$ passivation layer is formed, which blocks the incorporation of $\mathrm{Na}$ ions and electrons. On the other hand, during lithiation there are more the nucleation sites for the further penetration of lithium, and consequently, for the formation of a nano-composites consisting of $\mathrm{Li}_{2} \mathrm{O}$ and $\mathrm{Ni}$ nanoparticles. Compared to the thick, highly crystalline $\mathrm{Na}_{2} \mathrm{O}$ passivation layers observed during sodiation, this nanocomposite phase of $\mathrm{Li}_{2} \mathrm{O}$ and $\mathrm{Ni}$ nanoparticles includes a high fraction of grain boundaries and interfaces, which supports the enhanced transport of both $\mathrm{Li}^{+}$ions and electrons. It is anticipated that a proper doping on the $\mathrm{NiO}$ anti-sites can affect the local strain and that a recently developed Li-activation method can help to break the passivation layers. ${ }^{33}$ These approaches may help to improve the reaction kinetics of $\mathrm{NiO}$.

In summary, we have investigated the reaction mechanism of a typical transition metaloxide, $\mathrm{NiO}$, through a correlated set of multi-scale methods, including an electrochemical study and a synchrotron study of a real battery system, the in situ TEM observation of a half-cell, and an ab initio MD simulation. Dramatic differences were observed between sodiation and lithiation. In particular, only the shrinking-core mode was observed during sodiation using in situ TEM. Further sodiation was blocked by a passivation layer of $\mathrm{Na}_{2} \mathrm{O}$ that formed at an early stage, and this, in turn, resulted in sluggish kinetics. MD simulation shows that the sodiation pathway that leads to this shrinking-core mode originates from a layer-by-layer reaction that 
occurs during the insertion of $\mathrm{Na}$ ions. This study offers mechanistic insights into the processes of sodiation of a model metal-oxide system, and may guide further studies of Na-based electrode materials.

\section{Methods}

Sample preparation. The NiO nanosheets were synthesized using a solvothermal method, aided with an alcohol pseudo-supercritical drying technique. ${ }^{34}$

Electrochemical measurements. Composite electrodes, prepared with $80 \mathrm{wt} \%$ active material, 10wt\% polyvinylidene fluoride (PVDF), and 10wt\% acetylene carbon black in N-methyl-2pyrrolidone (NMP) were cast on to copper current collectors. 2032-type coin cells were assembled in an argon-filled glove box, using the composite electrode as the positive electrode and the $\mathrm{Na}$ (or Li) metal as the negative electrode. A Celgard separator 2400 and a $1 \mathrm{M} \mathrm{NaPF}_{6}$ (or $\mathrm{LiPF}_{6}$ ) electrolyte solution in 1:1 w/w ethylene carbonate/dimethyl carbonate were used to fabricate coin cells. Batteries were tested on computer-controlled VMP3 channels (BioLogic). $1 \mathrm{C}$ was defined as full discharging $\mathrm{NiO}$ in $1 \mathrm{~h}$, which corresponds to a theoretical specific current density of $718 \mathrm{~mA} \mathrm{~g}^{-1}$.

Synchrotron XAS. XAS measurements were performed on the 31-pole wiggler beamline 10-1 at Stanford Synchrotron Radiation Lightsource (SSRL) using a ring current of $350 \mathrm{~mA}$, and a $10001 \cdot \mathrm{mm}^{-1}$ spherical grating monochromator with $20 \mu \mathrm{m}$ entrance- and exit-slits, providing $\sim 10^{11} \mathrm{ph} \cdot \mathrm{s}^{-1}$ at $0.2 \mathrm{eV}$ resolution in a $1 \mathrm{~mm}^{2}$ beam spot. During the measurements, all samples of battery electrodes were attached to an aluminum sample holder using conductive carbon. Data were acquired under ultrahigh vacuum $\left(10^{-9}\right.$ Torr $)$ in a single load at room temperature, using total electron yield (TEY) and fluorescence yield (FY). The sample drain current was collected 
for TEY. A silicon diode (IRD AXUV-100) was used to collect the fluorescence yield (FY) positioned near the sample surface. Contributions from visible light were minimized carefully before the acquisition of data, and all spectra were normalized by the current from freshly evaporated gold on a fine grid positioned upstream of the main chamber.

TEM characterization. The in situ TEM electrochemical cell was incorporated into a Nanofactory TEM-STM specimen holder (Figure 2a), in which $\mathrm{NiO}$ nanosheets dispersed on a TEM half-grid with amorphous carbon support are analogous to the NiO-C composite electrode, $\mathrm{Na}$ (or Li) metal is coated on to a piezo-driven $\mathrm{W}$ probe as the counter electrode, with a thin layer of $\mathrm{Na}_{2} \mathrm{O}$ (or $\mathrm{Li}_{2} \mathrm{O}$ ) formed on $\mathrm{Na}$ (or $\mathrm{Li}$ ) metal as the solid electrolyte. The $\mathrm{Na}$ (or $\mathrm{Li}$ ) and $\mathrm{NiO}$ were loaded on to the holder in an Ar-filled glove box and then transferred to the TEM column using a sealed Ar bag to avoid exposing them to air. During the in situ electrochemical tests, a constant negative DC potential (1-3V) was applied to $\mathrm{NiO}$ electrode against the $\mathrm{Na}$ (or Li) source during lithiation, and the lithiation processes were captured in real-time in either the TEM- or STEM-mode. Electron tomography of the in situ lithiated sample was acquired in the ADF-STEM mode with a tilt series from $-70^{\circ}$ to $70^{\circ}$ and $1^{\circ}$ intervals. The in situ measurements and tomography were performed on a JEOL 2100F TEM operated at $200 \mathrm{kV}$. The highresolution STEM imaging and analytical EELS were conducted on a Hitachi HD2700C STEM operated at $200 \mathrm{kV}$, and equipped with a probe aberration corrector (spatial resolution $<1 \AA$, energy resolution $0.35 \mathrm{eV}$ ). The 3D tomography was reconstructed using the e-Tomo software suite written by Robert Hovden et al. (Cornell Muller group) and visualized by Avizo 6.3.

First-principles calculations. The ab initio Molecular Dynamics simulations were undertaken using the Vienna Ab initio Simulation Package (VASP) within the projector augmented-wave approach with the Perdew-Burke-Ernzerhof generalized-gradient approximation (GGA) to the 
density functional theory (DFT). The computer model consisted of a NiO (001) surface-slab $(8.4 \AA \times 8.4 \AA \times 10.5 \AA)$ of 48 formulae of $\mathrm{NiO}$ in contact with an amorphous Li metal slab $(8.4$ $\AA \times 8.4 \AA \times 12.8 \AA)$ of $54 \mathrm{Li}$ atoms, or a Na metal slab $(8.4 \AA \times 8.4 \AA \times 10.5 \AA)$ of $24 \mathrm{Na}$ atoms. The MD simulations of lithiation and sodiation were performed with a time step of 2 fs for 20-60 ps at $600 \mathrm{~K}$, using a NPT ensemble.

\section{ASSOCIATED CONTENT}

\section{Supporting Information}

Additional details of S/TEM, XAS, DFT calculation, and in situ movies. This material is available free of charge via the Internet at http://pubs.acs.org.

\section{AUTHOR INFORMATION}

\section{Corresponding Authors}

*E-mail: yfmo@umd.edu

* E-mail: hxin@bnl.gov

* E-mail:dsu@bnl.gov

\section{Author Contributions}

K.H. and F.L. contributed equally to this work. K.H., F.L., Y.M., H.L.X. and D.S. conceived and designed the experiments. K.H. and D.S. performed the in situ and ex situ S/TEM experiments with the help of J.L.. R.L. and H.L.X. performed electron tomography and EELS acquisition and analysis. F.L. and M.M.D. performed the electrochemical measurements. Y.Z. and Y.M. performed the theoretical modeling. F.L., D.N. and T.-C.W. performed the synchrotron X-ray measurements. F.L. and R.M.R. synthesized the NiO samples. K.H., Y.M. H.L.X., F.L. and D.S. discussed the scope of the manuscript. K.H. prepared the figures with the help from X.Y. and X.-Q.Y.. D.S., K.H., Y.M., H.L.X., and F.L. wrote the manuscript with help from M.M.D. and E.A.S. All authors participated in discussions of the results. D.S. led the project.

\section{Notes}

The authors declare no competing financial interests.

\section{ACKNOWLEGMENTS}


The authors thank Prof. Ju Li and Prof. Andrew Rappe for helpful discussions, and thank Dr. Woodhead for proofreading. This research used resources of the Center for Functional Nanomaterials, which is a U.S. DOE Office of Science Facility, at Brookhaven National Laboratory under Contract No. DE-SC0012704. F.L. and M.M.D. were supported by the Assistant Secretary for Energy Efficiency and Renewable Energy, Office of Vehicle Technologies of the U.S. DOE under Contract No. DE-AC02-05CH11231 under the Batteries for Advanced Transportation Technologies (BATT) Program. The synchrotron X-ray work carried out at the Stanford Synchrotron Radiation Lightsource, SLAC National Accelerator Laboratory, was supported by the U.S. DOE under Contract No. DE-AC02-76SF00515. X.Y. and X.-Q.Y. were supported by the U.S. DOE, the Assistant Secretary for Energy Efficiency and Renewable Energy, Office of Vehicle Technologies under Contract No. DE-SC00112704. Y.Z. and Y.M. acknowledge the support of the Minta Martin award at the University of Maryland, and the computational resources from the Extreme Science and Engineering Discovery Environment (XSEDE) supported by National Science Foundation Grant No. TG-DMR130142 and from the University of Maryland supercomputing resources.

\section{REFERENCES}

1. Armand, M.; Tarascon, J. M. Nature 2008, 451, 652-657.

2. Dunn, B.; Kamath, H.; Tarascon, J. M. Science 2011, 334, 928-935.

3. Tarascon, J. M. Nat.Chem. 2010, 2, 510-510.

4. Goodenough, J. B.; Kim, Y. Chem Mater. 2010, 22, 587-603.

5. N. Nitta, F. Wu, J. T. Lee, G. Yushin, Mater. Todav. 2015, 18, 252-264.

6. Pan, H.; Hu, Y. S.; Chen, L. Enerov Environ.Sci. 2013, 2, 2338-2360.

7. Slater, M. D.; Kim, D.; Lee, E.; Johnson, C. S. Adv._Eunct.Mater. 2013, 23, 947-958.

8. Kim, S. W.; Seo, D. H.; Ma, X.; Ceder, G.; Kang, K. Adv.EnergvMater. 2012, 2, 710-721.

9. Hong, S. Y.; Kim, Y.; Park, Y.; Choi, A.; Choi, N. S.; Lee, K. T.; Enerov Environ. Sci. 2013, 6, 2067-2081. 
10. Alcantara, R.; Jaraba, M.; Lavela, P.; Tirado, J. L. Chem. Mater. 2002, 14, 2847-2848.

11. Poizot, P.; Laruelle, S.; Grugeon, S.; Dupont, L.; Tarascon, J. M. Nature 2000, 407, 496-499.

12. Cabana, J.; Monconduit, L.; Larcher, D.; Palacín, M. R. Adv. Mater. 2010, 22, E170-E192.

13. Mo, Y.; Ong, S. P.; Ceder, G. Chem. Mater. 2014, 26, 5208-5214.

14. Sun, Y.; Zhao, L.; Pan, H.; Lu, X.; Gu, L.; Hu, Y. S.; Li, H;. Armand, M.; Ikuhara, Y.; Chen, L.; Huang, X. Nat. Commun. 2013, 4, 1870.

15. Zhu, C.; Mu, X.; van Aken, P. A.; Yu, Y.; Maier, J. Angew. Chem. Int. Ed. 2014, 53, 2152-.

16. Klein, F.; Jache, B.; Bhide, A.; Adelhelm, P. Phys. Chem. Chem. Phys. 2013, 15, $15876-15887$.

17. Huang, J. Y.; Zhong, L.; Wang, C. M.; Sullivan, J. P.; Xu, W.; Zhang, L. Q.; Mao, S. X.; Hudak, N. S.; Liu, X. H.; Subramanian, A.; Fan, H.; Qi, L.; Kushima, A.; Li, J. Science 2010, 330, 1515-1520.

18. Liu, X. H.; Wang, J. W.; Huang, S.; Fan, F.; Huang, X.; Liu, Y.; Krylyuk, S.; Yoo, J.; Dayeh, S. A.; Davydov, A. V.; Mao, S. X.; Picraux, S. T.; Zhang, S.; Li, J.; Zhu, T.; Huang, J. Y. Nat. Nanotech. 2012, 7, 749-756.

19. Liu, Y.; Hudak, N. S.; Huber, D. L.; Limmer, S. J.; Sullivan, J. P.; Huang, J. Y. Nano Lett. 2011, 11, 4188-4194.

20. Kushima, A.; Liu, X. H.; Zhu, G.; Wang, Z. L.; Huang, J. Y.; Li, J. Nano Lett. 2011, 11, 4535-4541.

21. McDowell, M. T.; Ryu, I.; Lee, S. W.; Wang, C.; Nix, W. D.; Cui, Y. Adv. Mater. 2012, 24, 6034-6041.

22. McDowell, M. T.; Lu, Z.; Koski, K. J.; Yu, J. H.; Zheng, G.; Y. Cui, Nano Lett. 2015, 15, 1264-1271. 
23. Nie, A.; Gan, L. Y.; Cheng, Y.; Asayesh-Ardakani, H.; Li, Q.; Dong, C.; Tao, R.; Mashayek, F.; Wang, H. T.; Schwingenschlogl, U.; Klie, R. F.; Yassar, R. S. ACS Nano 2013, 7, $6203-6211$.

24. Gu, M.; Kushima, A.; Shao, Y.; Zhang, J. G.; Liu, J.; Browning, N. D.; Li, J.; Wang, C. Nano Lett. 2013, 13, 5203-5211.

25. He, K.; Zhou, Y.; Gao, P.; Wang, L.; Pereira, N.; Amatucci, G. G.; Nam, K. W.; Yang, X. Q.; Zhu, Y.; Wang, F.; Su, D. ACS Nano 2014, 8, 7251-7259.

26. Liu, Y.; Fan, F.; Wang, J.; Liu, Y.; Chen, H.; Jungjohann, K.; Xu, Y.; Zhu, Y.; Bigio, D.; Zhu, T.; Wang, C. Nano Lett. 2014, 14, 3445-3452.

27. He, K.; Xin, H. L.; Zhao, K.; Yu, X.; Nordlund, D.; Weng, T. C.; Li, J.; Jiang, Y.; Cadigan, C. A.; Richards, R. M;. Doeff, M. M.; Yang, X. Q.; Stach, E. A.; Li, J.; Lin, F.; Su, D. Nano Lett. 2015, 15, 1437-1444.

28. Lin, F.; Nordlund, D.; Weng, T. C.; Zhu, Y.; Ban, C.; Richards, R. M.; Xin, H. L. Nat. Commun. 2014, 5, 3358.

29. Bosesnberg, U.; Marcus, M. A.; Shukla, A. K.; Yi, T.; McDermott, E.; Teh, P. F.; Srinivasan, M.; Moewes, A.; Cabana, J. Sci. Rep. 2014, 4, 7133.

30. Lin, F.; Markus, I. M.; Doeff, M. M.; Xin, H. L. Sci. Rep. 2014, 4, 5694.

31. Xu, K. Chem. Rev. 2004, 104, 4303-4417.

32. Berry, C. R. Phys. Rev. 1952, 88, 596-599.

33. Kohandehghan, A.; Cui, K.; Kupsta, M.; Ding, J.; Lotfabad, E. M.; Kalisvaart, W. P.; Mitlin, D. Nano Lett. 2014, 14, 5873-5882.

34. Hu, J.; Zhu, K.; Chen, L.; Yang, H.; Li, Z.; Suchopar, A.; Richards, R. Adv. Mater. 2008, 20, 267-271. 


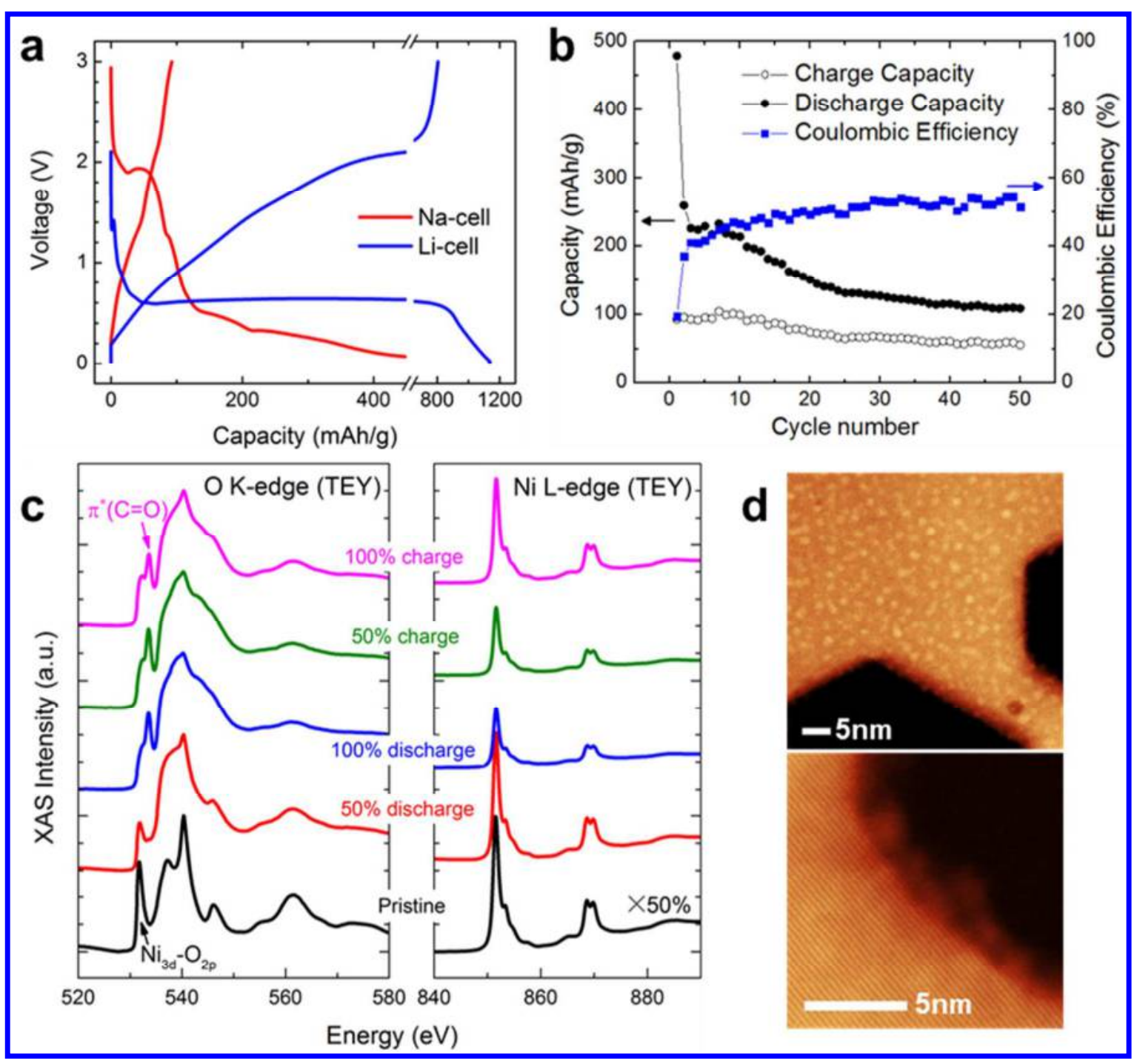

Figure 1. Cell performance and XAS measurements. (a) The first cycle charge-discharge voltage profiles of Na- (red) and Li- (blue) half-cells at rates of 0.1C. (b) Cycling performance and Coulombic efficiency of the Na half-cell. (c) XAS spectra in total electron yield (TEY) mode for $\mathrm{NiO}$ electrodes at different SOC $(0,50 \%, 100 \%$ of the first discharge and $50 \%$ and $100 \%$ of the subsequent charge). The left panel shows the normalized TEY intensities of the oxygen K-edges and the right panel shows the absolute TEY intensities of the nickel L-edges (the pristine profile is scaled to $50 \%$ of its absolute intensity). (d) STEM images of the sodiated electrode showing $\mathrm{Ni}$ nanoparticles on the surface of a $\mathrm{NiO}$ nanosheet. 


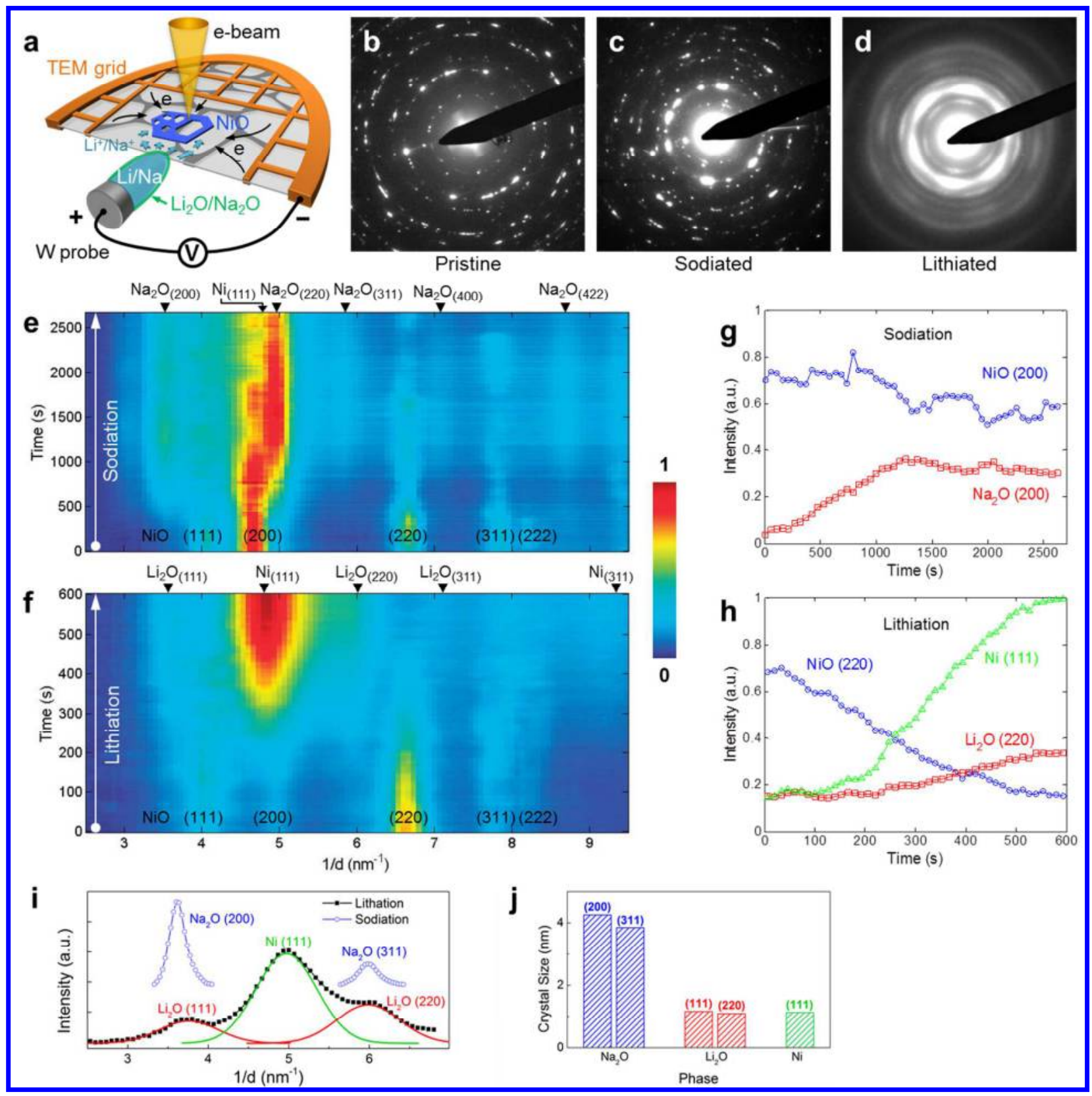

Figure 2. Phase evolution during in situ sodiation and lithiation. (a) Schematic illustration shows the in situ setup of a dry electrochemical cell inside a TEM (details referred to in Methods). Electron-diffraction patterns for (a) pristine, (b) sodiated, and, (c) lithiated samples. Colored intensity profiles as function of reaction time for (e) sodiation, and (f) lithiation processes. The profiles correspond to the radial integration of electron diffraction at varying time frames, with the Bragg peaks labeled. Intensity profiles of selected Bragg reflections during (g) sodiation, and (h) lithiation, showing phase evolution of $\mathrm{NiO}, \mathrm{Na}_{2} \mathrm{O}, \mathrm{Li}_{2} \mathrm{O}$ and Ni. (i) Selected Bragg peak profiles showing narrower FWHM of $\mathrm{Na}_{2} \mathrm{O}$ reflections than $\mathrm{Li}_{2} \mathrm{O}$ and $\mathrm{Ni}$, which further correlate to the crystal size shown in (j). 


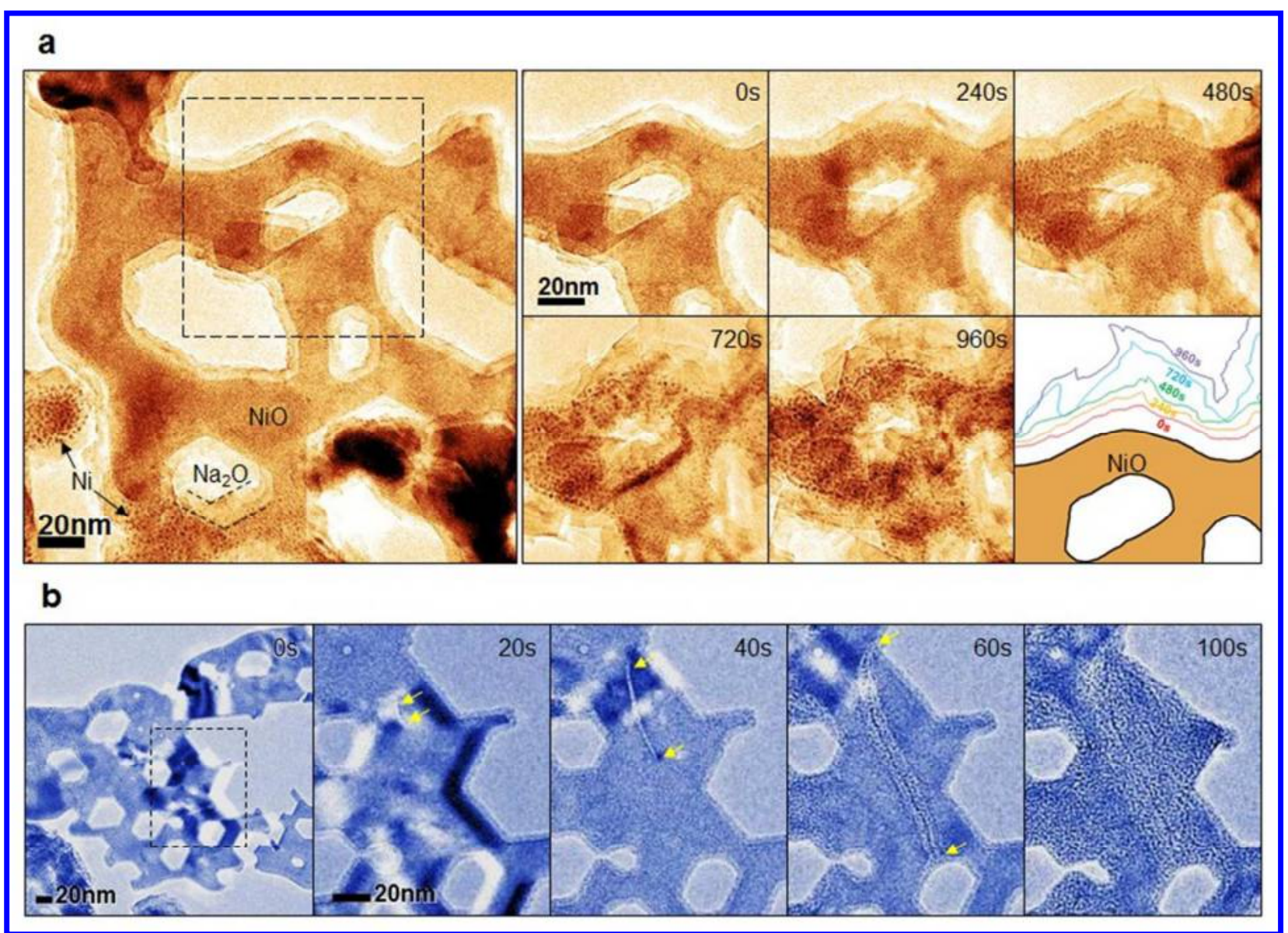

Figure 3. Morphological evolution during in situ sodiation and lithiation. TEM imaging series captured in real time show morphological evolution during an in situ (a) sodiation, and (b) lithiation, of $\mathrm{NiO}$ nanosheet electrodes. The initial low-magnification images in both series display the entire area of observation, and the latter enlarged image series correspond to the boxed regions to reveal representative features in detail. The last image in (a) shows the outline of an $\mathrm{Na}_{2} \mathrm{O}$ layer at sequential time. The arrows in (b) indicate the propagation of a finger penetration during lithiation. ${ }^{27}$ 


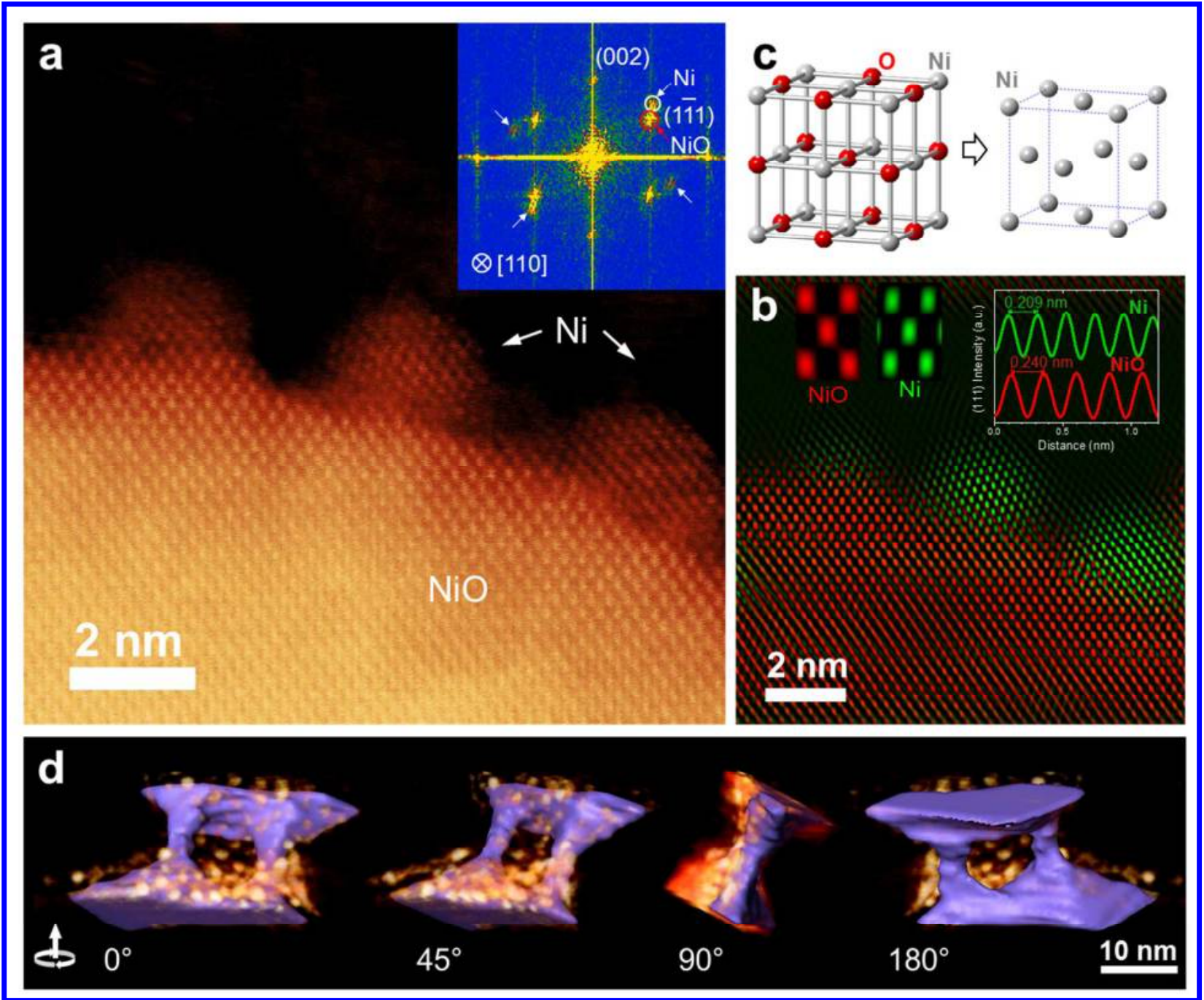

Figure 4. Atomic structures after sodiation. (a) STEM-ADF image showing the atomically resolved crystal structures of the sodiated electrode materials in a cross-sectional view. The bulk material is an unreacted $\mathrm{NiO}$ single-crystal with reduced $\mathrm{Ni}$ single-crystal nanoparticles on the surface, both on the zone axis of [110] direction. The inset FFT showing two distinct sets of diffraction spots, attributed to $\mathrm{NiO}$ and $\mathrm{Ni}$ (indicated by arrows) as labeled. (b) Reconstructed atomic structures of (a) after separating the $\mathrm{NiO}$ (red) and $\mathrm{Ni}$ (green) reflections by imposing inverse-FFT filters. The inset images of crystal unit cells (top-left) indicate that the lattice parameter decreases as $\mathrm{NiO}$ (red) transforms into $\mathrm{Ni}$ (green), consistent with the decrease of the lattice spacing between (111) planes (top-right). (c) Models of crystal structures for $\mathrm{NiO}$ and Ni. (d) Reconstructed 3D tomograms at different viewing angles showing that the reduced $\mathrm{Ni}$ nanoparticles (in orange) are attached on the surface of an incompletely reacted $\mathrm{NiO}$ slab (in purple). No sodiation occurred at the back side of $\mathrm{NiO}$ contacting the carbon film (not shown in reconstruction). See Movie 4 in Supporting Information for full details. 


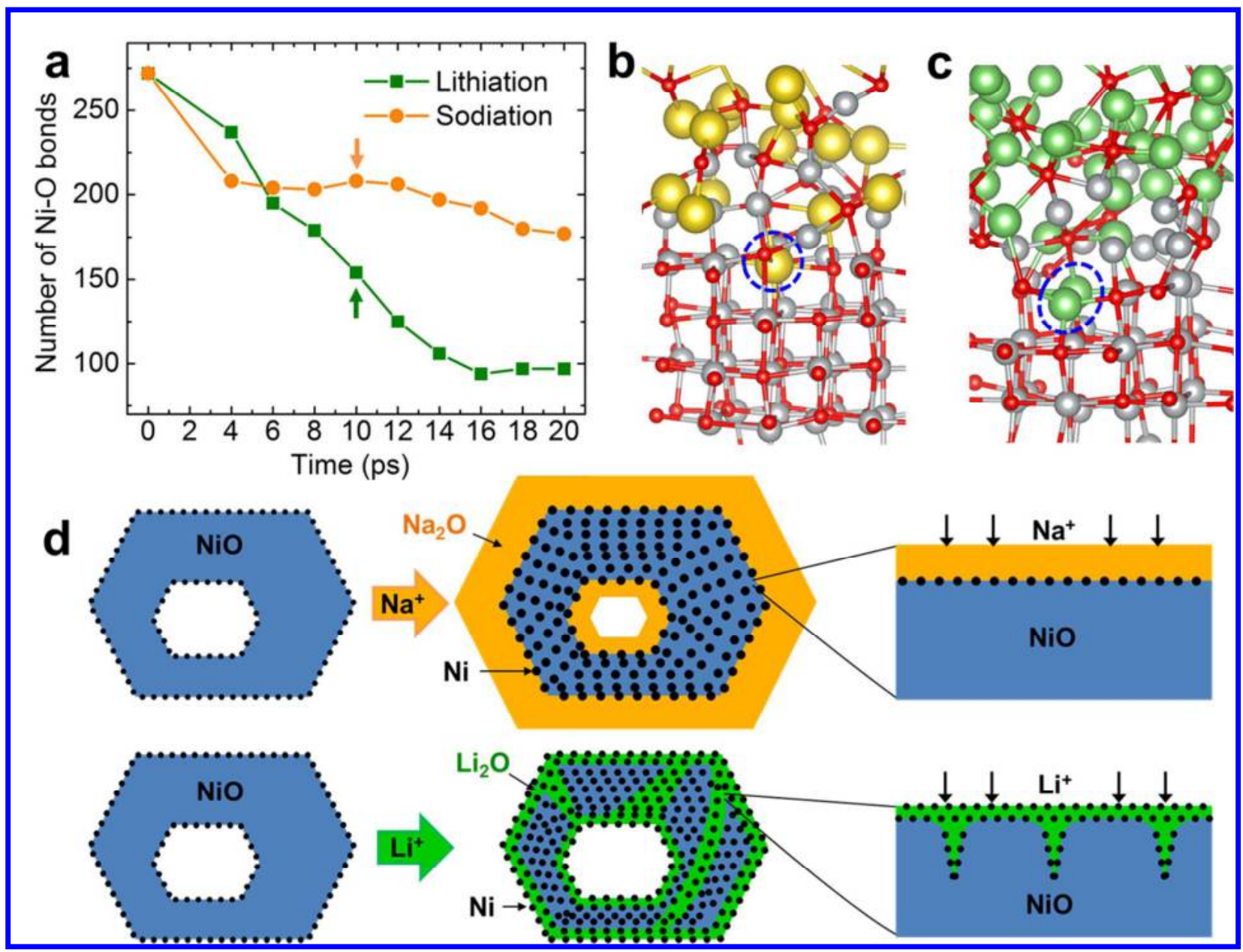

Figure 5. Ab intio MD simulations. (a) The change in the total number of Ni-O bonds over time during the MD simulations for the lithation and sodiation of NiO. The snapshots of (b) sodiatedand (c) lithiated $\mathrm{NiO}$ surfaces at 10 ps showing the formation of $\mathrm{Li} / \mathrm{Na}$ anti-site defects (highlighted in circles) in NiO. (d) Schematic cartoons showing different reaction modes between sodiation and lithiation. 


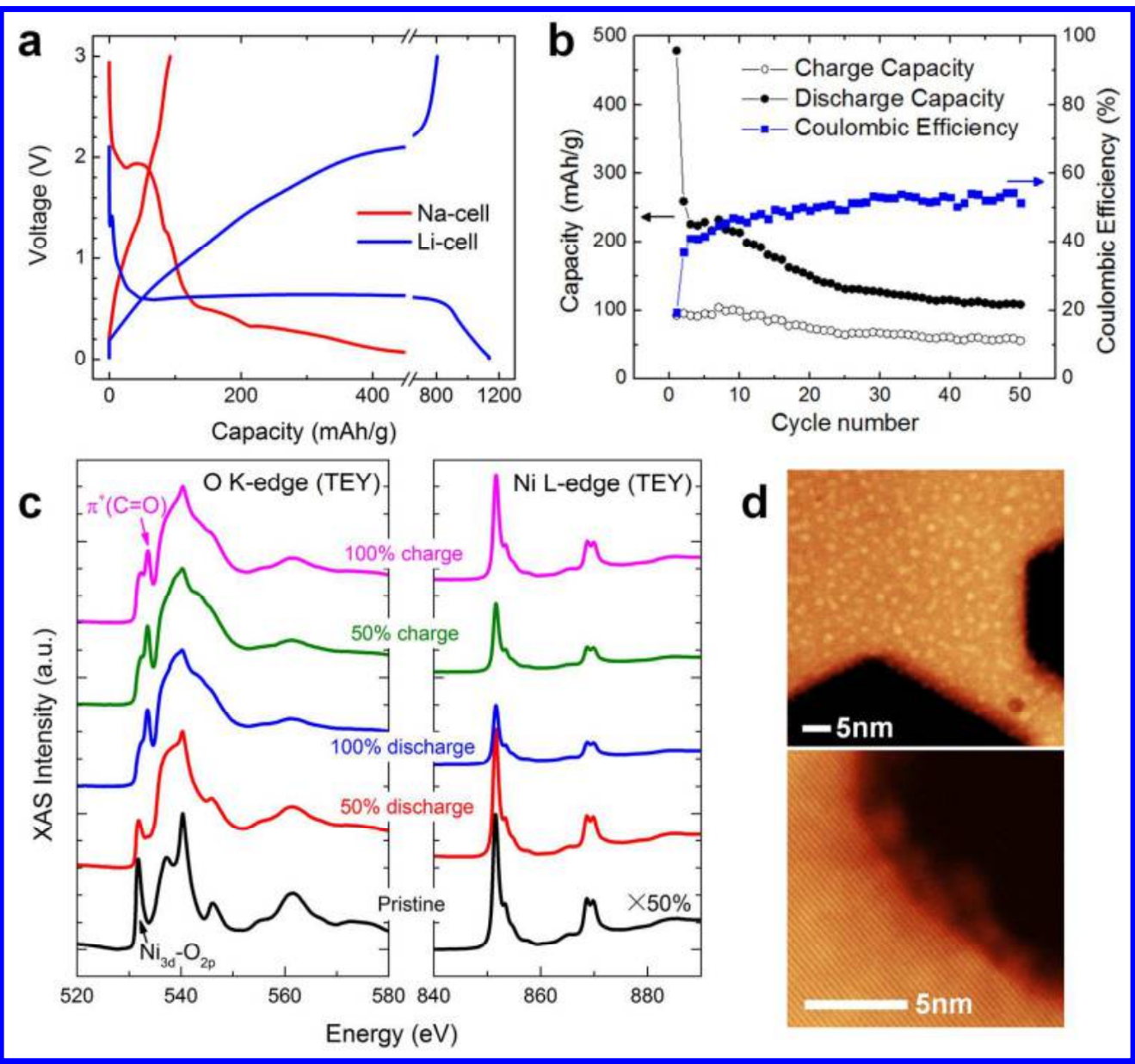

Figure with high resolution $177 \times 165 \mathrm{~mm}(300 \times 300$ DPI) 


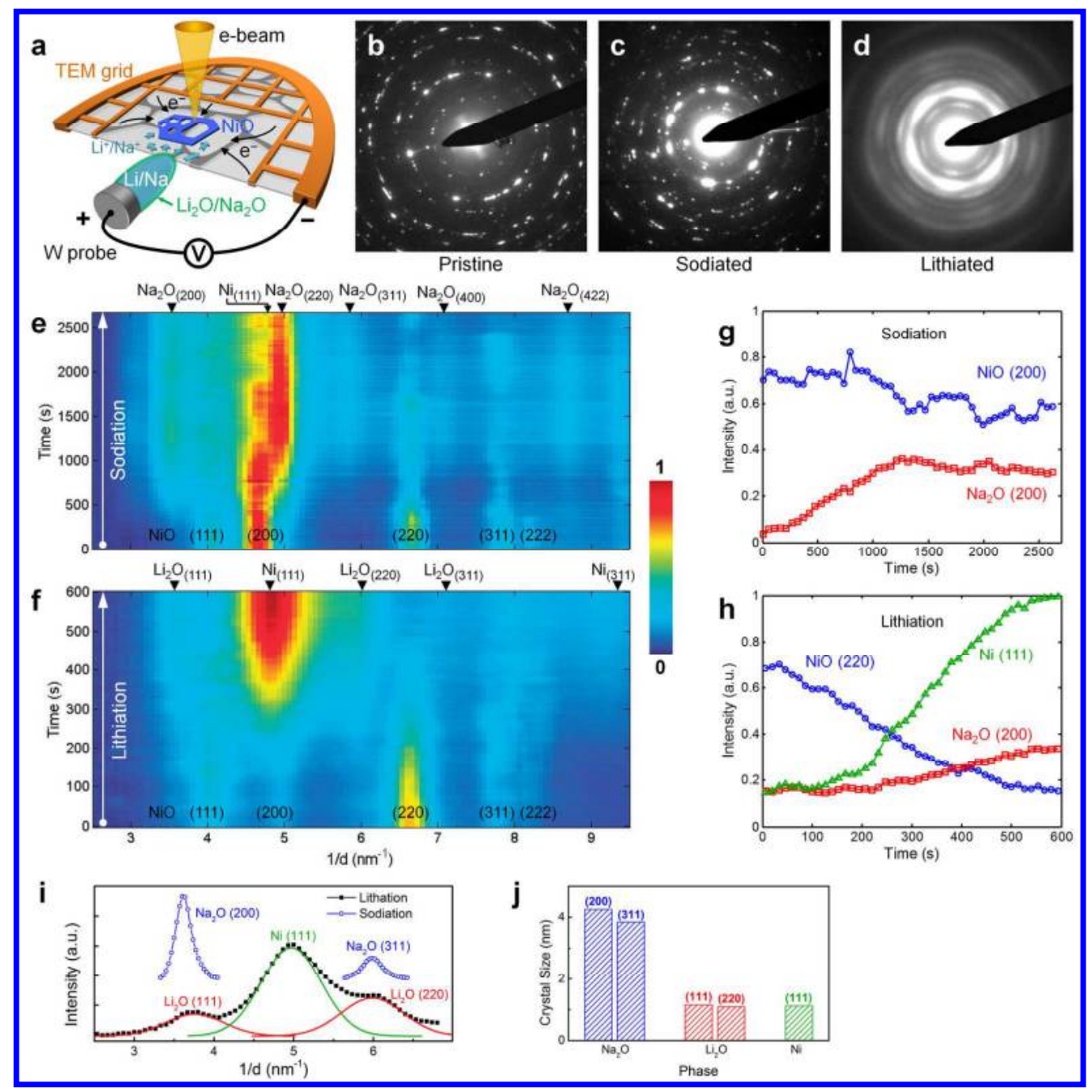

Figure with high resolution $177 \times 178 \mathrm{~mm}(300 \times 300 \mathrm{DPI})$ 


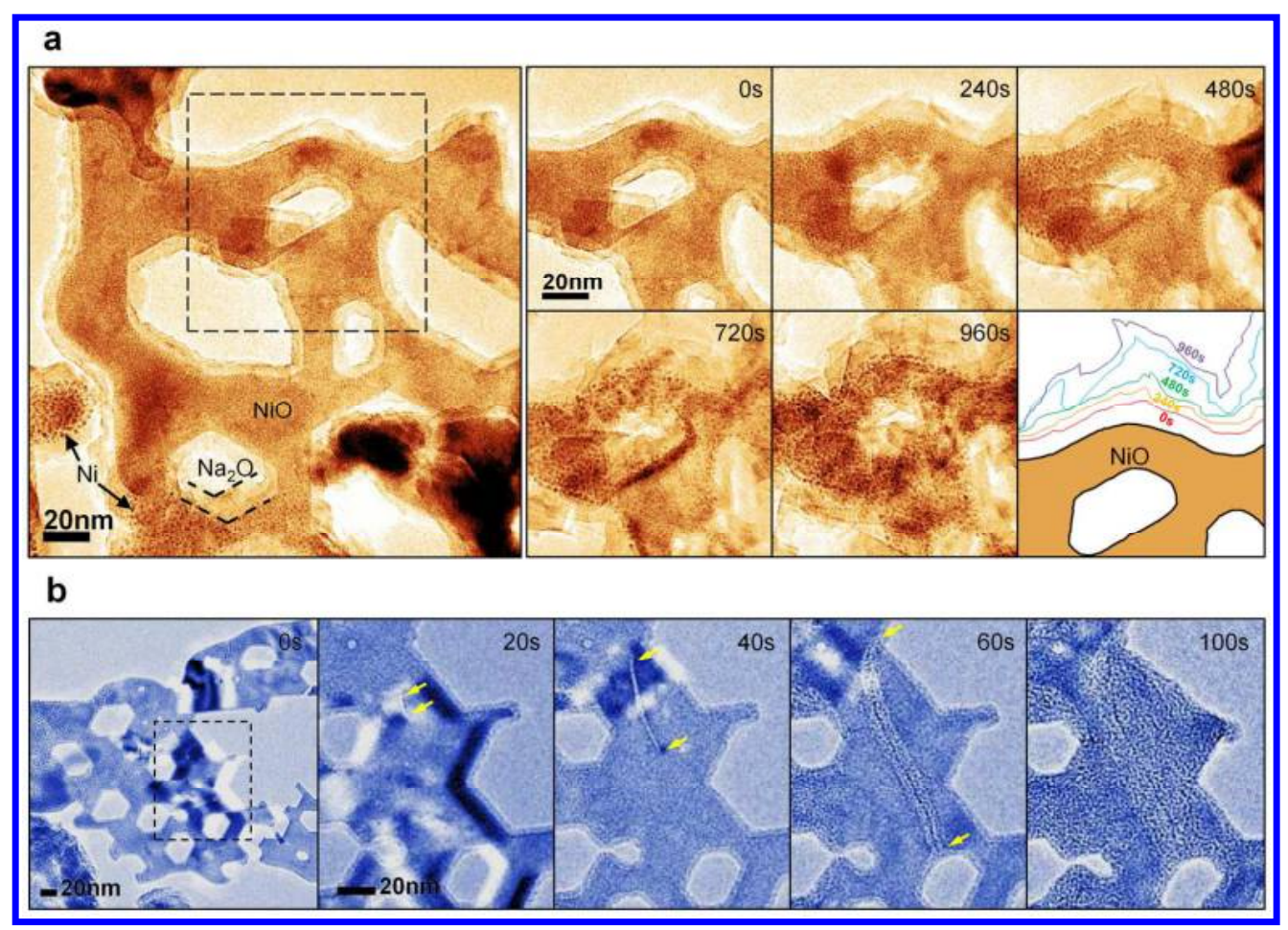

Figure with high resolution $177 \times 127 \mathrm{~mm}(300 \times 300$ DPI) 


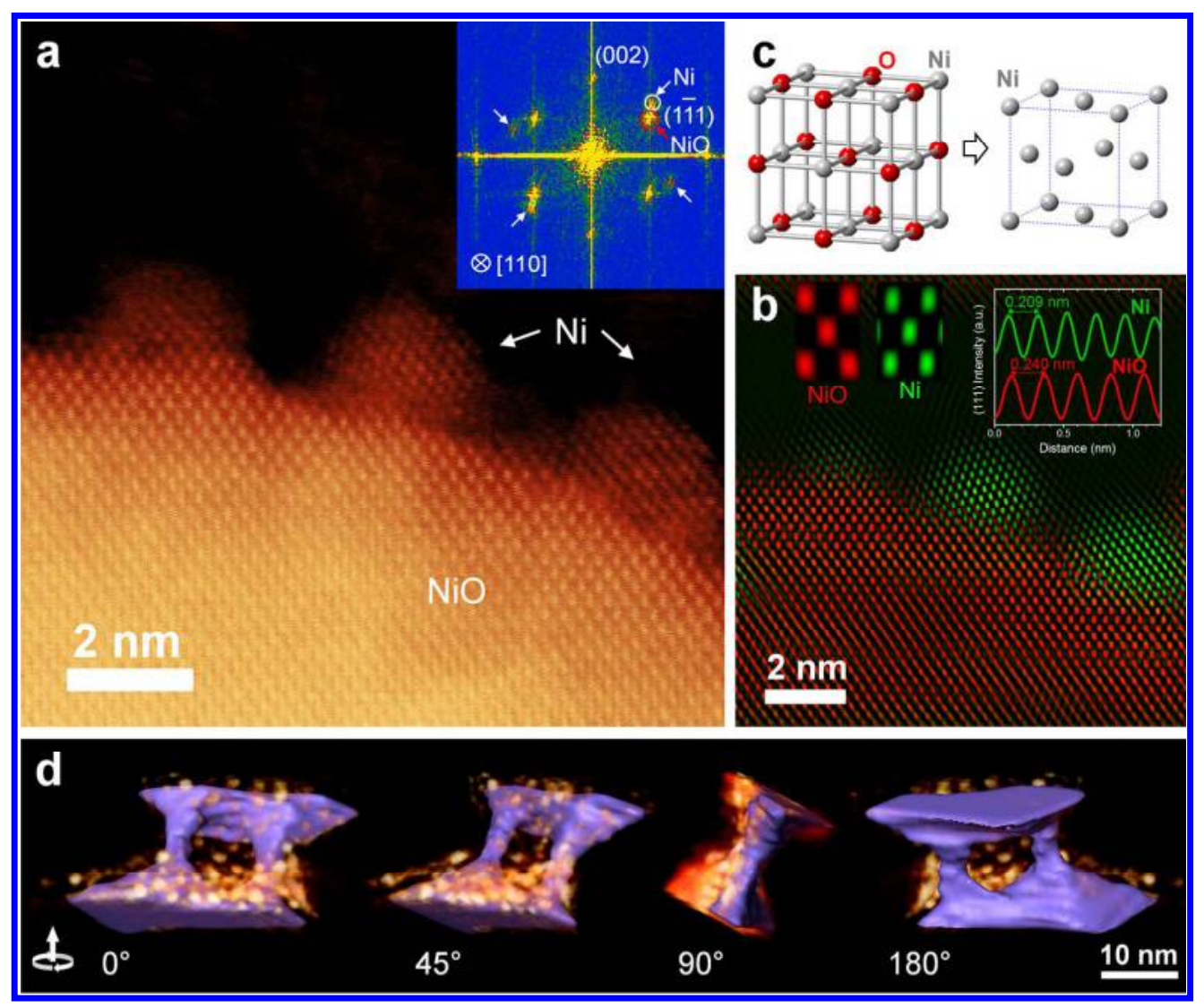

Figure with high resolution

$177 \times 147 \mathrm{~mm}$ (300 x 300 DPI) 


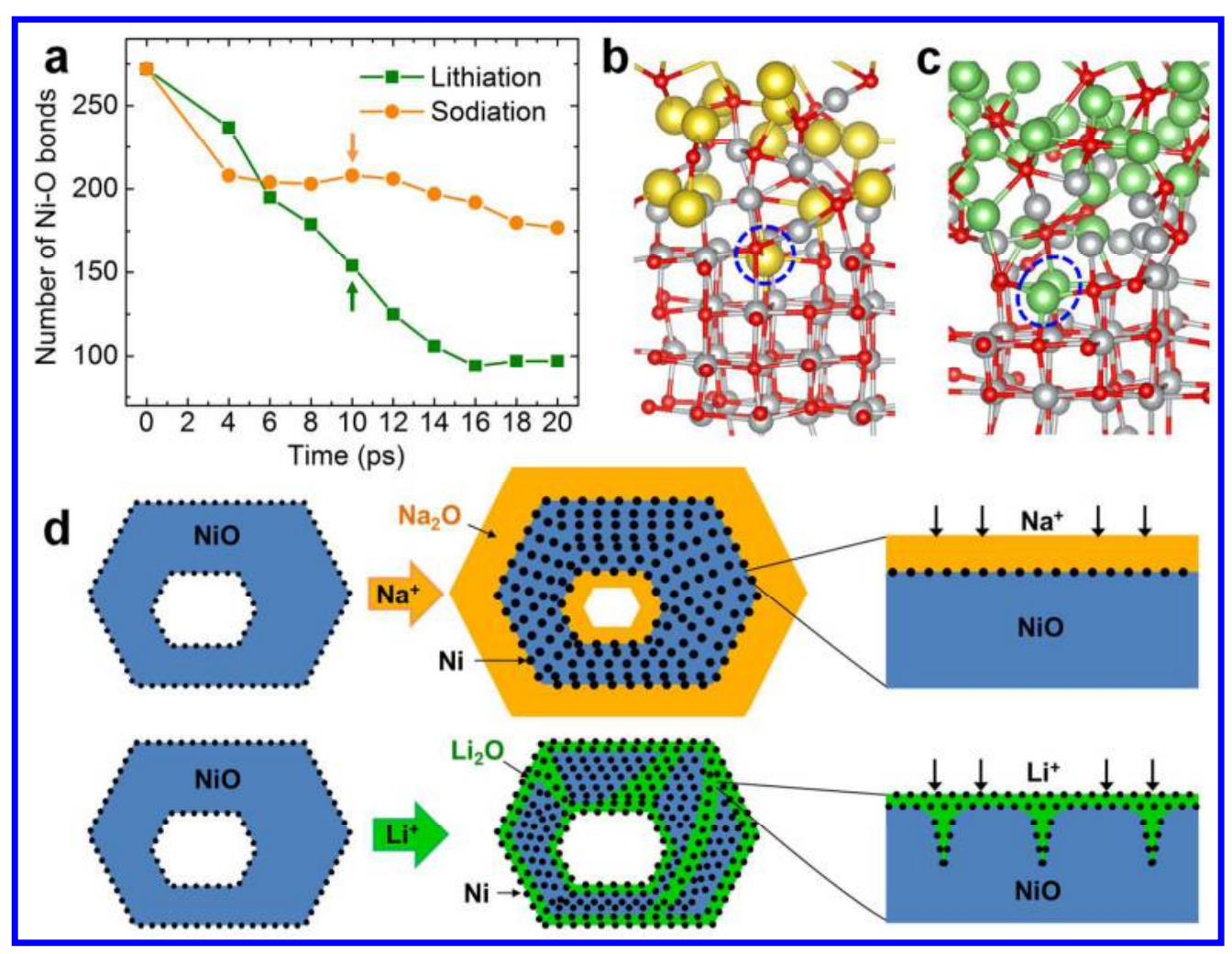

Figure with high resolution

$177 \times 136 \mathrm{~mm}$ (300 x 300 DPI) 


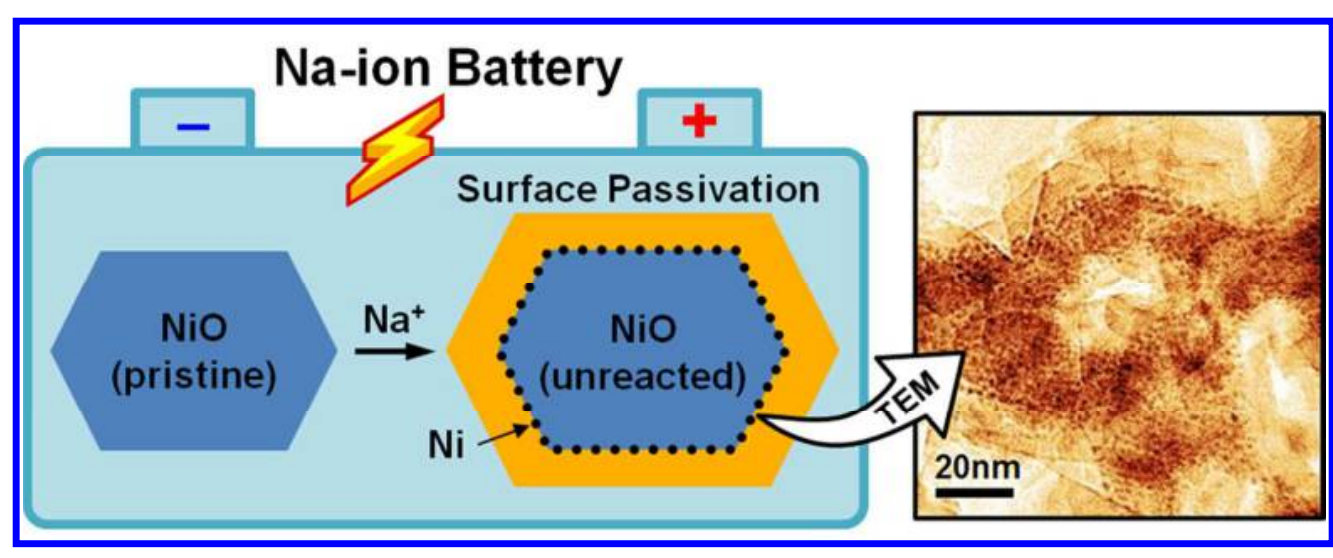

$88 \times 34 \mathrm{~mm}(300 \times 300$ DPI $)$ 